\title{
Chromoendoscopy using toluidine blue plus Lugol's solution for early diagnosis of esophageal premalignant lesions and superficial neoplasms in high-risk patients
}

\author{
Jean Félix PIÑERÚA-GONSÁLVEZ1,2, Rosanna del Carmen ZAMBRANO-INFANTINO ${ }^{1,3}$ and Sylvia BENÍTEZ ${ }^{1}$
}

Received 11/10/2018

Accepted 18/1/2019

ABSTRACT - Background - Esophageal cancer is the eighth most common cancer. The prognosis is bleak in patients with advanced stages. Patients with early disease have a better prognosis than those with advanced stage. There are several techniques for the screening of premalignant and superficial lesions including chromoendoscopy. Objective - This article aimed to determine the effectiveness of chromoendoscopy with toluidine blue combined with Lugol's solution for diagnosis of esophageal premalignant and superficial neoplastic lesions in high risk patients. Methods - Routine white light upper endoscopy was performed. Toluidine blue was sprayed from the gastroesophageal junction to $20 \mathrm{~cm}$ of the dental arch. Then the uptake dye areas were characterized. Later Lugol's solution was sprayed. Areas with less-intense staining were characterized. Biopsy of the toluidine blue capturing areas and areas with less-intense staining of Lugol's solution were taken. In the cases where lesions were not evidenced after application of dyes, biopsies four quadrants of the esophageal mucosa were taken. The samples were evaluated by a digestive pathologist. Results - Barrett's esophagus was the most common premalignant lesion and the early neoplastic lesion was adenocarcinoma with a sensitivity of $100 \%$, specificity $85.7 \%$, positive predictive value $30 \%$, negative predictive value $100 \%$, positive likelihood ratio 7 negative likelihood ratio 0 . Conclusion - Chromoendoscopy with toluidine blue combined with Lugol's solution is a useful tool in the screening of esophageal premalignant lesions and superficial neoplasms.

HEADINGS - Esophageal neoplasms. Tolonium chloride. Staining and labeling. Early detection of cancer.

\section{INTRODUCTION}

Esophageal cancer is the eighth most common cancer with an estimated 456,000 new cases by 2012 . It is the sixth leading cause of cancer-related death in the world. This disease has a high mortality rate with an estimated 400,000 deaths worldwide in 2012. Esophageal cancer is fourfold more common and slightly more lethal in men than women ${ }^{(1)}$. There are two main histological kinds of esophageal cancer, squamous cell carcinoma and adenocarcinoma (ADC). Squamous cell type is the most common histological kind of esophageal cancer, whereas in certain developed countries like Australia, Finland, France, United States and United Kingdom the ADC is the predominant variety ${ }^{(2)}$. Incidence rates of squamous cell carcinoma have been reported as high as 100 cases per 100,000 annually in an area known as the "Asian esophageal cancer belt" (region extending from northeastern China to the Middle East $)^{(3,4)}$. The epidemiology of esophageal cancer in developed countries has changed over the last forty years. Squamous cell carcinoma was responsible for more than $90 \%$ of cases of esophageal carcinoma in the United States. In 1975 the ADC affected four people per million, in 2001 the rate had increased to twenty-three people per million, representing the cancer with the fastest rates of growth in United States, according to the National Cancer Institute ${ }^{(5)}$. In South America, the esophageal cancer age-standardized incidence rate is 4.3 cases per 100,000 inhabitants, with the highest incidence in Brazil, Uruguay, Cuba and Argentina. In Venezuela for 2012, age-standardized incidence rate was 1.2 and 313 deaths were recorded for esophageal cancer, with an age-standardized mortality rate of 1.2 deaths per 100,000 inhabitants $^{(6)}$

The prognosis of this disease is bleak, as more than $50 \%$ of patients already have advanced stage disease with unresectable and/ or metastatic disease at the time of diagnosis. Patients with limited mucosal or submucosal disease have a better prognosis than those with advanced stage. However, early detection of this disease is difficult because it is often shown as a flat and/or isochromatic lesion in conventional white light endoscopy ${ }^{(7,8)}$.

Currently, there are several techniques for screening of premalignant and superficial lesions including exfoliative cytology, chromoendoscopy and Narrow Band Imaging (Olympus Medical System Corporation, Tokyo, Japan $)^{(9)}$. Chromoendoscopy aims to facilitate the visualization and detection of dysplastic and malignant lesions in the gastrointestinal tract, which may be difficult to distinguish from the normal mucosa ${ }^{(10)}$.

This article aimed to determine the effectiveness of chromoendoscopy with toluidine blue in combination with Lugol's solution in the diagnosis of esophageal premalignant and superficial neoplastic lesions in high risk patients. 


\section{METHODS}

This was a prospective and transversal study. We enrolled patients who met the selection criteria from the gastroenterology consultation of Hospital Militar "Dr. Carlos Arvelo", Caracas, Venezuela, between January and June 2015. Variables were evaluated in two times, when the endoscopy was performed and having the results of histopathology.

Selection criteria included: Symptoms of gastroesophageal reflux of more than 5 years of evolution, accentuated smoking habits (>10 cigarettes per day), alcohol consumers of more than $80 \mathrm{gr}$ daily, history of head and neck cancer, history of head and neck radiation therapy and history of caustic ingestion. Exclusion Criteria were as follow: iodine allergy, hypothyroidism, hyperthyroidism and pregnant women. This study was approved by the ethical review board of Hospital Militar "Dr. Carlos Arvelo". All patients were fully informed about the procedure and provided written informed consent before the endoscopy.

\section{Procedural technique}

The procedure was performed in endoscopic unit. Upper digestive endoscopy was performed with an Olympus EVIS GIFQ145 videogastroscope. Conventional endoscopy was performed first. Following $1 \%$ acetic acid was used as a mucolytic agent, which was sprayed over the mucosa using spraying catheter $\left(\right.$ Glo-Tip $^{\circledR}$, Cook Medical $\left.{ }^{\circledR}\right)$ from the gastroesophageal junction to $20 \mathrm{~cm}$ of the dental arch and was waited for one minute. The procedure was then repeated with application of $1 \%$ toluidine blue and waited for one minute. The mucosa was washed with water. Endoscopic characterization of the stained areas was performed. Lugol's solution was then sprayed from the gastroesophageal junction to the $20 \mathrm{~cm}$ of the dental arcade and waited for 1 minute and washed again with water. Areas with less-intense staining were characterized. Biopsy of the toluidine blue capturing areas and areas with less-intense staining of Lugol's solution were taken. In the cases where there was no evidence of lesions after application of the dyes, we proceeded to take biopsies of four quadrants of the esophageal mucosa, each $10 \mathrm{~cm}$ from the gastroesophageal junction to $20 \mathrm{~cm}$ of the dental arch. The samples were evaluated by a digestive pathologist specialist. Specialized intestinal metaplasia with low or high grade dysplaia, squamous dysplasia, $\mathrm{ADC}$ and squamous cell carcinoma were defined as a positive histological finding.

\section{Statistical analysis}

Once the histopathological results were obtained, it was calculated sensitivity, specificity, positive predictive value (PPV), negative predictive value (NPV), positive and negative likelihood ratio. The $95 \%$ confidence interval (CI) for sensitivity, specificity, NPV and PPV was calculated. For the analysis of statistical significance, the Fisher exact test was applied for dichotomous qualitative variables. A $P$ value $<0.05$ was considered statistically significant. Statistical analyzes were calculated using IBM ${ }^{\circledR}$ SPSS $^{\circledR}$ Statistics 21.0.

\section{RESULTS}

A total of 52 patients were included in the study, 27 (51.9\%) were female. The mean age was 52.67 years with a standard deviation of 11.87 years. The most frequent indication for endoscopy was gastroesophageal reflux symptoms for more than 5 years $(67.3 \%)$
(TABLE 1). There were no patients with history of premalignant or neoplastic lesions of the esophagus.

TABLE 1. Baseline patient features.

\begin{tabular}{lc}
\hline Characteristic & $\mathbf{n}(\%)$ \\
\hline Mean age (years) & $52.67 \pm 11.87$ \\
Gender & \\
Male & $25(48.1)$ \\
Female & $27(51.9)$ \\
Indications for endoscopy & \\
Gastroesophageal reflux symptoms & $35(67.3)$ \\
Smoking & $11(21.2)$ \\
Alcohol consumers * & $1(1.9)$ \\
History of head and neck cancer & $5(9.6)$ \\
\hline * Alcohol intake $>80$ gr daily. &
\end{tabular}

In conventional white-light endoscopy, the most frequent findings were normal esophageal mucosa in 39 patients $(75 \%)$ followed by erosive esophagitis grade A according to Los Angeles Classification $^{(11)}$ in nine patients $(17.3 \%)$, endoscopically suspected esophageal metaplasia in three patients $(5.8 \%)$ and slightly elevated lesion 0 -IIa according to Paris classification ${ }^{(12)}$ in one patient $(1.9 \%)$.

After application of the dyes, the esophageal mucosa showed areas of blue uptake and areas with less-intense staining of Lugol's solution in 10 patients (19.2\%) (FIGURE 1).

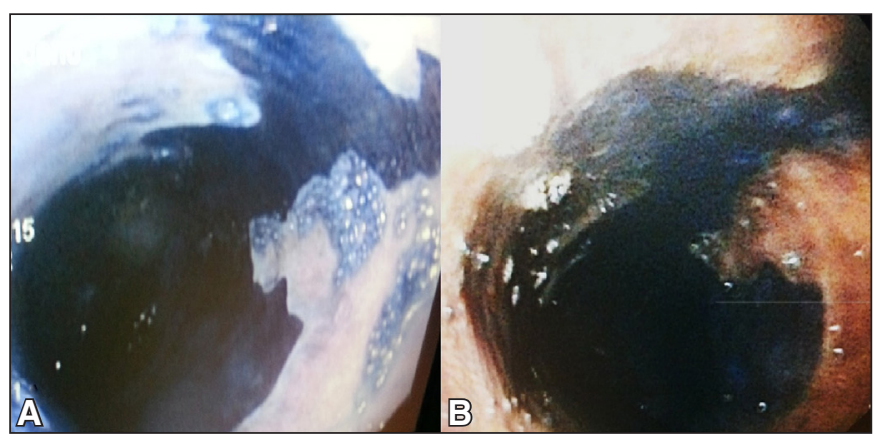

FIGURE 1. Chromoendoscopy in a patient with endoscopically suspected esophageal metaplasia. In (A) appearance of the mucosa after application of toluidine blue. A mucosal tongue stained blue is observed. In (B) mucosal appearance after adding Lugol's solution. A clear delimitation between the affected mucosa and the rest is observed.

The histological findings of areas with toluidine blue uptake and with less-intense staining of Lugol's solution were specialized intestinal metaplasia with low-grade dysplasia in two patients $(20 \%)$, specialized intestinal metaplasia without dysplasia in one patient $(10 \%)$ and adenocarcinoma in one patient $(10 \%)$ (TABLE 2). The histology of samples taken in the 42 patients who did not present suspicious areas after chromoendoscopy demonstrated findings compatible with reflux esophagitis in 32 patients $(76.1 \%)$ and normal mucosa in the remain patients.

The sensitivity of chromoendoscopy to toluidine blue in combination with Lugol was 100\% (95\% CI 43.8\%-100\%), specificity was $85.7 \%(95 \%$ CI $73.3 \%-92.9 \%),(P=0.01)$ (TABLE 3$)$. The PPV was $30 \%$ and the NPV was $100 \%$. The positive likelihood ratio was 7 and the negative likelihood ratio was 0 . 
TABLE 2. Histological findings of the areas with toluidine blue uptake and with less-intense staining of Lugol's solution.

\begin{tabular}{lc}
\hline Finding & $\mathrm{n}(\%)$ \\
\hline Normal & $0(0)$ \\
Reflux esophagitis & $6(60)$ \\
SIM without dysplasia & $1(10)$ \\
SIM with low-grade dysplasia & $2(20)$ \\
SIM with high-grade dysplasia & $0(0)$ \\
ADC & $1(10)$ \\
Squamous cell carcinoma & $0(0)$ \\
\hline
\end{tabular}

SIM: specialized intestinal metaplasia; ADC: adenocarcinoma.

TABLE 3. Correlation between histological diagnosis of premalignant and neoplastic lesions and chromoendoscopic findings.

\begin{tabular}{lccc}
\hline & & \multicolumn{2}{c}{ Premalignant lesion/Neoplasm } \\
\cline { 2 - 4 } & & Negative, $\mathbf{n}(\%)$ & Positive, $\mathbf{n}(\%)$ \\
\hline \multirow{2}{*}{ Chromoendoscopy } & Positive & $7(14.3)$ & $3(100)$ \\
& Negative & $42(85.7)$ & $0(0)$ \\
\hline
\end{tabular}

Positive Chromoendoscopy: toluidine blue capturing areas and areas with less-intense staining of Lugol's solution. Negative chromoendoscopy: None suspicious areas after application of the dyes.

\section{DISCUSSION}

Diagnosis of premalignant lesions and superficial neoplasms in the esophagus is critical, because it increases the survival by permitting earlier potentially curative interventions, reducing local recurrences and of distant metastases risks ${ }^{(13)}$. Chromoendoscopy has become an useful tool for the screening of premalignant and superficial lesions in the digestive tract by improving the recognition of changes in the mucosal surface, which leads to a better delimitation of the margins of the lesions as well as the detection of lesions not previously observed with conventional white light endoscopy ${ }^{(10)}$.

Lugol's solution is an iodine-based absorptive staining that has an affinity for glycogen in non-keratinized squamous epithelium. It is used primarily for the identification of squamous dysplasia and squamous cell cancer of the esophagus in early stages. Areas with glycogen depletion such as dysplasia, squamous cell carcinoma, Barrett's epithelium, and inflammation remain unblemished or weakly stained ${ }^{(14)}$. Chromoendoscopy with Lugol's solution has improved the detection rate of squamous dysplasia and squamous cell carcinoma in early stages in patients with esophageal symptoms (reflux symptoms, dysphagia and globus sensation) compared to conventional endoscopy in both high-risk population and low risk-population ${ }^{(15,16)}$. In the study published by Shiozaki et al. 178 patients with head and neck cancer were screened for synchronous and metachronous primary esophageal cancer using chromoendoscopy with Lugol's solution. In that study 9 patients had esophageal cancer (5.1\%). The majority of lesions (9 of 13 lesions) were not detectable by radiologic or conventional endoscopy ${ }^{(17)}$. In a similar study published by Kominek et al. 132 patients with primary squamous cell carcinoma of the head and neck were evaluated for early synchronous esophageal cancer. Using chromoendoscopy with Lugol, squamous cell carcinoma of the esophagus was diagnosed in two patients and low-grade and high-grade dysplasia in three patients ${ }^{(18)}$.
Toluidine blue is a basic absorptive dye that stains the nuclei of the cells. It can identify malignant cells, due to increased mitotic activity and increased core/cytoplasmic ratio. This staining has been used mainly for the detection of squamous dysplasia and carcinoma of the oral cavity and to a lesser extent in the esophagus. The pathological areas are stained blue ${ }^{(14)}$. Chobanian et al. in 1987 published a study in which Barrett's esophagus was detected by upper digestive endoscopy in 58 patients with gastroesophageal reflux disease, first inspecting the mucosa without dye, then applying toluidine blue and then taking biopsies both the areas that were Stained like and the areas that that were not. The sensitivity of conventional endoscopy was $86 \%$ with a specificity of $88 \%$; while the sensitivity for detection of Barrett's esophagus following the application of toluidine blue was $98 \%$ with a specificity of $80 \% \%^{(19)}$.

The combined use of toluidine blue with Lugol's solution has been studied in the detection of premalignant and neoplastic lesions in the oral cavity. Nagaraju et al. performed a study in which 30 patients with clinical suspicion of premalignant lesions and 30 patients with suspected malignant lesions in the oral cavity were evaluated using Lugol's solution combined with toluidine blue. In that study the sensitivity for the detection of premalignant lesions was $100 \%$, specificity $60 \%$, positive predictive value $93 \%$ and negative predictive value $100 \%$. In the case of malignant lesions the sensitivity was $92.7 \%$, specificity $60 \%$, positive predictive value $96 \%$ and negative predictive value $43 \%{ }^{(20)}$.

In the current study, a combination of toluidine blue and Lugol's solution was used for the detection of both premalignant lesion and superficial neoplasms of the esophagus. The combination of these dyes showed a sensitivity of $100 \%$ and a specificity of $85.7 \%$. The combined use of toluidine blue with Lugol's solution allowed a better delimitation of lesions in esophagus. This is because toluidine blue produces a royal blue coloration in the pathological mucosa, while the healthy mucosa acquires a pale blue hue. Subsequent to applying Lugol's solution, the healthy mucosa with high glycogen content acquires a brown tone, which allows a clear demarcation between the healthy and pathological mucosa.

The most frequent premalignant lesion diagnosed in this study was Barrett's esophagus and ADC as superficial neoplasm. However, neither squamous dysplasia nor squamous cell carcinoma were diagnosed, which is probably related to the short period of collection, which limited the inclusion of more patients with risk factors for this pathology $(32.7 \%)$.

The main limitation of the current study was the size of the sample. This was because the small number of patients who attended the outpatient clinic and met the inclusion criteria. The small sample size may reduce the potency of the screening method proposed in this study.

In conclusion, the present study demonstrated that chromoendoscopy with toluidine blue and Lugol's solution has a high sensitivity, specificity and negative predictive value, which, together with its relatively low cost, simplicity and safety makes it an useful tool in the screening of esophageal premalignant lesions and superficial neoplasms.

Additional studies with larger samples should be performed to strengthen the results reported in this study, especially in the population with risk factors for squamous cell carcinoma, because in the present study there was no a representative group of patients for this subgroup of lesions. 


\section{Authors' contribution}

Piñerúa-Gonsálvez JF, Zambrano-Infantino RC: performed cases, collected data and drafted the mansucript. Piñerúa-Gonsálvez JF: statistical analysis. Benitez S: reviewed and approved final draft of the mansucript.

\section{Orcid}

Jean Félix Piñerúa-Gonsálvez. Orcid: 0000-0002-6033-0242.

Rosanna del Carmen Zambrano-Infantino: Orcid: 0000-00016876-5948.

Sylvia Benitez: Orcid: 0000-0002-1367-8289.

Piñerúa-Gonsálvez JF, Zambrano-Infantino RC, Benítez S. Utilização da cromoendoscopia com azul de toluidina mais solução de Lugol para diagnóstico precoce de lesões pré-malignas esofágicas e neoplasias superficiais em pacientes de alto risco. Arq Gastroenterol. 2019;56(1):41-4.

RESUMO - Contexto - O câncer de esôfago é o oitavo câncer mais comum. O prognóstico é sombrio em pacientes com estágios avançados. Pacientes com doença precoce têm um melhor prognóstico do que aqueles com estágio avançado. Existem várias técnicas para a triagem de lesões pré-malignas e superficiais, incluindo cromoendoscopia. Objetivo - Este artigo objetivou determinar a efetividade da cromoendoscopia com azul de toluidina combinada com a solução de Lugol para o diagnóstico de lesões neoplásicas pré-malignas e superficiais esofágicas em pacientes de alto risco. Métodos - A endoscopia de luz branca de rotina foi realizada de forma rotineira. O azul do toluidina foi pulverizado desde a junção gastroesofágica até 20 $\mathrm{cm}$ da arcada dentária. As áreas impregnadas pela tintura da tomada foram então caracterizadas. Mais adiante a solução de Lugol foi pulverizada. Áreas com coloração menos intensa foram caracterizadas. Foram realizadas biópsias das áreas de captura de azul de toluidina e áreas com coloração menos intensa da solução de Lugol. Nos casos onde as lesões não foram evidenciadas após a aplicação das tinturas, foram feitas biópsias em quatro quadrantes da mucosa esofágica. As amostras foram avaliadas por um patologista especializado. Resultados - O esôfago de Barrett foi a lesão pré-maligna mais frequente e a lesão neoplásica precoce foi adenocarcinoma com sensibilidade de $100 \%$, especificidade de $85,7 \%$, valor preditivo positivo de $30 \%$, valor preditivo negativo $100 \%$, razão de verossimilhança positiva 7 e razão de verossimilhança negativa 0 . Conclusão - A cromoendoscopia com azul de toluidina combinada com a solução de Lugol é uma ferramenta útil na triagem de lesões pré-malignas esofágicas e neoplasias superficiais.

DESCRITORES - Neoplasias esofágicas. Cloreto de tolônio. Coloração e rotulagem. Detecção precoce de câncer.

\section{REFERENCES}

1. Zhang Y. Epidemiology of esophageal cancer. World J Gastroenterol. 2013;19: 5598-606.

2. Lepage C, Rachet B, Jooste V, Faivre J, Coleman MP. Continuing rapid increase in esophageal adenocarcinoma in England and Wales. Am J Gastroenterol 2008;103:2694-9.

3. Napier KJ, Scheerer M, Misra S. Esophageal cancer: A Review of epidemiology, pathogenesis, staging workup and treatment modalities. World J Gastrointest Oncol. 2014;6:112-20.

4. Eslick GD. Epidemiology of esophageal cancer. Gastroenterol Clin North Am. 2009;38:17-25.

5. Brown LM, Devesa SS, Chow WH. Incidence of adenocarcinoma of the esophagus among white Americans by sex, stage, and age. J Natl Cancer Inst. 2008;100:1184-7.

6. Ferlay J, Soerjomataram I, Ervik M, Dikshit R, Eser S, Mathers C, et al. GLOB OCAN 2012 v1.0, cancer incidence and mortality worldwide: IARC cancer base no. 11. International Agency for Research on Cancer, Lyon; 2014.

7. Goda K, Dobashi A, Yoshimura N, Kato M, Aihara H, Sumiyama K, et al. Narrow-Band Imaging Magnifying Endoscopy versus Lugol Chromoendoscopy with Pink-Color Sign Assessment in the Diagnosis of Superficial Esophageal Squamous Neoplasms: A Randomised Noninferiority Trial. Gastroenterol Res Pract. 2015;2015:639462.

8. Enzinger PC, Mayer RJ. Esophageal cancer. N Engl J Med. 2003;349:2241-52.

9. Nicolas Perez D, Quintero E, Parra Blanco A. [Screening the at-risk population for squamous cell carcinoma of the esophagus]. [Article in Spanish]. Gastroenterol Hepatol. 2005;28:337-46.

10. Trivedi PJ, Braden B. Indications, stains and techniques in chromoendoscopy QJM. 2013;106:117-31.

11. Armstrong D, Bennett JR, Blum AL, Dent J, De Dombal FT, Galmiche JP, et al. The endoscopic assessment of esophagitis: a progress report on observer agreement. Gastroenterology. 1996;111:85-92.
12. Endoscopic Classification Review G. Update on the paris classification of superficial neoplastic lesions in the digestive tract. Endoscopy. 2005;37:570-8.

13. Chen LQ, Hu CY, Ghadirian P, Duranceau A. Early detection of esophageal squamous cell carcinoma and its effects on therapy: an overview. Dis Esophagus. 1999;12:161-7.

14. ASGE Technology Committee, Wong Kee Song LM, Adler DG, Chand B, Conway JD, Croffie JMB, et al. Chromoendoscopy. Gastrointest Endosc. 2007;66: 639-49.

15. Dawsey SM, Fleischer DE, Wang GQ, Zhou B, Kidwell JA, Lu N, et al. Mucosal iodine staining improves endoscopic visualization of squamous dysplasia and squamous cell carcinoma of the esophagus in Linxian, China. Cancer. 1998:83:220-31

16. Shao Y, Yu ZL, Ji M, Wu YD, Yu YZ, Liang XM, et al. Lugol chromoendoscopic screening for esophageal dysplasia/early squamous cell carcinoma in patients with esophageal symptoms in low-risk region in China. Oncology letters. 2015; 10:45-50.

17. Shiozaki H, Tahara H, Kobayashi K, Yano H, Tamura S, Imamoto H, et al Endoscopic screening of early esophageal cancer with the Lugol dye method in patients with head and neck cancers. Cancer. 1990;66:2068-71.

18. Kominek P, Vitek P, Urban O, Zelenik K, Halamka M, Feltl D, et al. Chromoendoscopy to detect early synchronous second primary esophageal carcinoma in patients with squamous cell carcinomas of the head and neck? Gastroenterol Res Pract. 2013;2013:236264.

19. Chobanian SJ, Cattau EL Jr, Winters C Jr, Johnson DA, Van Ness MM, Miremadi A, et al. In vivo staining with toluidine blue as an adjunct to the endoscopic detection of Barrett's esophagus. Gastrointest Endosc. 1987;33:99-101.

20. Nagaraju K, Prasad S, Ashok L. Diagnostic efficiency of toluidine blue with Lugol's iodine in oral premalignant and malignant lesions. Indian J Dent Res. $2010 \cdot 21 \cdot 218-23$. 